\title{
Structural Optimization of 3 MW Wind Turbine Blades Using a Two- Step Procedure
}

\author{
Kun-Nan Chen ${ }^{1, \mathrm{a}}$, Pin-Yung Chen ${ }^{1}$ \\ ${ }^{1}$ Department of Mechanical Engineering, Tungnan University, 22202, Taipei, Taiwan
}

Received 25 May 2010, Accepted 30 September 2010

\begin{abstract}
Modern large wind turbines, utilized to harness the kinetic energy of the wind, are rated at megawatts in output power. The design of large wind turbine blades must consider both their aerodynamic efficiency and structural robustness. This paper presents a two-step procedure for the optimum design of composite wind turbine blades. The results of the first step are the aerodynamically optimal cord lengths and twist angles of airfoils for the blade cross-sections along the blade spanwise direction. The second step yields optimal material distribution for the composite blade. A 3 MW wind turbine with blades having cross-sections of NREL S818, S825 and S826 airfoil types is demonstrated as the design example. Loaded by maximum forces and moments extracted from simulated time series, a parameterized finite element model of the aerodynamically optimized blade is created using the ANSYS software. The optimization results show that the initial blade model is an infeasible design due to a high level of the maximum stress, exceeding the upper limit of the stress constraint, but eventually the process converges to a feasible solution with the expense of increased total mass of the blade.
\end{abstract}

Key words: Wind turbine blade, Aerodynamic design, Structural optimization, Finite element analysis, Stress constraint

\section{Introduction}

Wind power has been one of the fastest growing renewable energy technologies throughout the world in recent years. Wind turbines, which are used to harness the kinetic energy of the wind, have two basic configurations: horizontal axis and vertical axis. Modern large wind turbines with output rated at megawatts (MW) predominantly have a horizontal axis. A horizontal-axis wind turbine equips a rotor (generally with two or three blades), a nacelle (housing the rotor shaft, gearbox, generator, electrical switch boxes and control systems), and a turbine tower. Based on the relative position of the rotor to the wind direction, horizontal-axis wind turbines can be further classified as upwind or downwind ones. A turbine rotor is made of a hub, a rotor shaft and blades that have good aerodynamic characteristics. For large wind turbines, turbine blades are usually made from composite materials to reduce the weight while attaining a reasonable strength to weight ratio. The design of large wind turbine blades must consider both their aerodynamic efficiency and structural robustness. Besides the circular shape at the blade root, the cross-sections along the spanwise direction of a blade have the shapes of airfoils. Early designs of wind turbine blades utilized airfoils intended originally for airplanes, such as the NACA series. Nowadays, except for some traditional shapes less sensitive to surface roughness, most blades use airfoils designed specifically for wind turbines, e.g., the NREL S series and DU series (Timmer [1]).

Maalawi and Badr [2] simplified the theoretical optimum values of airfoil cord lengths and twist angles for wind turbine blades, and suggested some practical shapes for the blades. Maalawi and Negm [3] proposed an objective func- tion that was a composite function of several natural frequencies for a turbine blade, and maximized this function to achieve the goal of decreasing steady state and transient responses. Díaz Casás et al. $[4,5]$ investigated a turbine blade aerodynamic problem in a form of multi-disciplinary optimization, using an evolutionary-based procedure. Jureczko et al. [6] combined the finite element method and genetic algorithm to minimize the weight of a turbine blade, with stress and blade tip displacement as constraints. Vitale and Rossi [7] developed a blade design program, based on the blade element theory (BET), to calculate the optimal aerodynamic blade shape of a rotor that would generate the requested power output, with the blade number, airfoil curves and wind field mean speed as inputs. Several technical reports (Malcolm and Hansen [8], Bir and Migliore [9], Griffin [10]) provide valuable information for large scale composite blade design.

This paper proposes a two-step procedure to produce blade designs that are optimal both in aerodynamics and in structure. The result of the first step is the optimum cord lengths and twist angles of airfoils of the blade cross-sections along the blade spanwise direction. The second step provides optimal material distribution for the composite blade, while the stress is kept within preset design stresses and the natural frequencies of the blade well separated from the rotor's rated speed, and the mass of the blade minimized. To achieve the objectives, a wind field simulation program, TurbSim, and a wind turbine dynamics code, FAST, are utilized to perform simulation. The maximum loads on the turbine blade are extracted and applied to a parameterized finite element model of a blade created in the ANSYS environment, and then the composite blade model is optimized. The two-step

${ }^{a}$ Corresponding author: knchen@mail.tnu.edu.tw 
procedure is demonstrated on a $3 \mathrm{MW}$, three-blade, horizontal-axis, upwind wind turbine, whose blades have crosssections of NREL airfoil types: S818, S825 and S826.

\section{The two-step procedure for wind turbine blade design}

The first step of this two-step procedure follows the blade design scheme suggested by Spera [11]. Assume that the following parameters are known: radius of the rotor $R$, number of blades of the rotor $N$, designed lift coefficient $C_{L d}$ for a particular airfoil, and the designed angle of attack $\alpha_{d}$ of the airfoil. Define $\omega$ as the angular speed of the rotor and the tip speed ratio $\lambda$ as the ratio of the blade tip speed of the rotor $(\omega R)$ to the mean wind speed in free stream $\left(V_{\infty}\right)$. For any given designed tip speed ratio $\lambda_{d}$, the cord length distribution of the airfoil along the blade spanwise has the form

$$
c_{r}=\frac{8 \pi r}{N C_{L d}}\left(1-\cos \phi_{r}\right)
$$

where

$$
\phi_{r}=\frac{2}{3} \tan ^{-1} \frac{1}{\lambda_{r}} \quad \text { and } \quad \lambda_{r}=\lambda_{d} \frac{r}{R}
$$

and $\lambda_{r}$ is called the local tip speed ratio at position $r, \phi_{r}$ the local inflow angle. The local twist angle of the airfoil at position $r$ is given as

$$
\beta_{r}=\phi_{r}-\alpha_{d}
$$

A rotor having blades with airfoils whose chord lengths and twist angles arranged according to Eqs. (1) and (3) will yield a maximum power output. Once the outer shape of the blade is determined, the material allocation of the composite blade can be decided in the second stage.

By setting the stress and frequency constraints and a minimum blade mass as the design objective, the structural optimization problem in the second phase can be defined as follows:

$$
\begin{array}{ll}
\text { Minimize } & m_{T} \\
\text { Subject to } & \sigma_{t} \leq \sigma_{d t} \\
& \sigma_{d c} \leq \sigma_{c} \\
& \left|f_{i}-f_{r}\right| \geq F_{m s}, \quad i=1,2, \ldots, s \\
& X_{j L} \leq x_{j} \leq X_{j U}, \quad j=1,2, \ldots, l
\end{array}
$$

where $m_{T}$ is the total mass of one blade; $\sigma_{t}$ and $\sigma_{c}$ the maximum tensile and minimum compressive stresses in the spanwise direction, respectively; $\sigma_{d t}$ the design tensile stress and $\sigma_{d c}$ the design compressive stress; $f_{i}, i=1, \ldots, s$ the $i$ th natural frequency of the blade and $s$ the number of modes considered; $f_{r}$ the wind turbine's rated rotor speed; $F_{m s}$ the minimum frequency separation specified; $x_{j}, j=1, \ldots, l$ the design variables with $l$ the number of design variables; and $X_{j U}$ and $X_{j L}$ the upper and lower bounds, respectively, of the design variables. Since the composite structure of the blade was treated macroscopically to simplify the problem, only tensile and compressive stresses were considered in the above formulation. The design stresses can be linked to the materials' ultimate strengths by $\sigma_{d t}=\sigma_{u t} / n_{f s}$ and $\sigma_{d c}=\sigma_{u c} / n_{f s}$, where $\sigma_{u t}$ and $\sigma_{u c}$ are the composite materials' ultimate tensile and compressive stresses, respectively, and $n_{f s}$ is total factor of safety, accounting for the general effect and the effects from aging, temperature, resin infusion and postcure (Germanischer Lloyd [12]).

\section{Design example of a $3 \mathrm{MW}$ wind turbine}

A three-blade, horizontal-axis, upwind wind turbine with a rated power of $3 \mathrm{MW}$, which is a modified version of a 3 MW turbine proposed by Malcolm and Hansen [8] and uses a scale-up version of a $20.15 \mathrm{~m}$ long blade in Bir and Migliore [9], was chosen as the design example. The turbine has a rotor with a diameter of $93.3 \mathrm{~m}$ and rated speed of $14.5 \mathrm{rpm}$, and a tilted rotor shaft of $5^{\circ}$. Also, the height of the rotor hub is $119 \mathrm{~m}$. Each rotor blade, which is $44.175 \mathrm{~m}$ long, has a circular cross-section from its root attaching the rotor hub to the 1.753-meter span location. Then the circular blade crosssections gradually transition to airfoil sections that have NREL airfoil types S818 at the 9.648-meter span location, $\mathrm{S} 825$ at $32.667-$ meter and $\mathrm{S} 826$ at 41.873 -meter and $44.175-$ meter (at the blade tip). Fig. 1 shows these NREL types of airfoils normalized by their cord lengths. Table 1 details the 14 cross-sections framing the blade. The section numbers 7 , $8,9,10$ and 12 in Table 1 are hybrid airfoils of the three basic types with different weighting factors to ensure proper transitions between two basic shapes.

For large-scaled wind turbines, two types of hollow rotor blades made of composite materials are commonly used: Type-A with web reinforcement as shown in Fig. 2 and Type-B with box-spar reinforcement as shown in Fig. 3. Although both types of blades were studied, only the Type-B's results are reported in this paper. Fig. 3 illustrates that a Type-A blade is composed of double-bias (DB), unidirectional, core and lining materials, and covered by an exterior coating of gelcoat with a layer of Nexus providing a smooth but absorbent surface in between for the painting of the gelcoat. Also shown in Fig. 3 are four different material models describing various parts of a blade cross-section. Table 2 lists the mechanical properties of the blade materials.

In this study, the wind turbine is undergone a turbulence with a mean wind speed of $25 \mathrm{~m} / \mathrm{s}$, which is assumed to be the maximum operation wind speed also known as the cutout speed. TurbSim (Jonkman and Buhl [13]), a full-field stochastic simulation program, was used to simulate the turbulence. Fig. 4(a) displays the simulated wind at the center of the hub in the direction perpendicular to the plane of rotation of the rotor $\left(V_{x}\right)$, using IEC normal turbulence model with the Kaimal spectrum. A wind turbine dynamics code, FAST (Jason and Marshall [14]), was utilized to perform wind turbine simulation. Fig. 4(b) shows the generator output power of the turbine. During operation, an active control was turned on to retain the rotor's rated speed and therefore the rated power. In Fig. 4 and thereafter, 600 seconds of time history were simulated, but the first 100 seconds were excluded to eliminate the initial effects and the rest $500 \mathrm{sec}-$ onds of time series analyzed. 


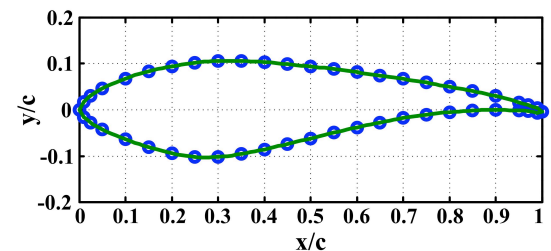

NREL S818 Airfoil

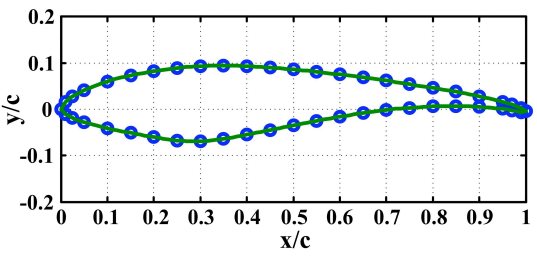

NREL S825 Airfoil

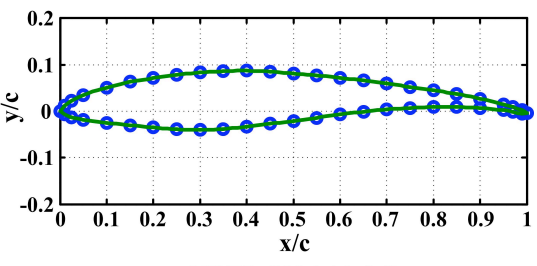

NREL S826 Airfoil

Fig. 1. NREL airfoil types: S818, S825 and S826

Table 1. Cross-sections of the blades

\begin{tabular}{cccc}
\hline Section & 1 & 2 & 3 \\
\hline Location $(\mathrm{m})$ & 0.0 & 1.051 & 1.206 \\
Shape & Circular & Circular & Circular \\
\hline Section & 4 & 5 & 6 \\
\hline Location $(\mathrm{m})$ & 1.467 & 1.754 & 9.648 \\
Shape & Circular & Circular & $\mathrm{S} 818$ \\
\hline Section & 7 & 8 & 9 \\
\hline Location $(\mathrm{m})$ & 14.251 & 18.854 & 23.457 \\
Shape & $\mathrm{S} 818 \times 0.8$ & $\mathrm{~S} 818 \times 0.6$ & $\mathrm{~S} 818 \times 0.4$ \\
& $+\mathrm{S} 825 \times 0.2$ & $+\mathrm{S} 825 \times 0.4$ & $+\mathrm{S} 825 \times 0.6$ \\
\hline Section & 10 & 11 & 12 \\
\hline Location $(\mathrm{m})$ & 28.060 & 32.667 & 37.270 \\
Shape & $\mathrm{S} 818 \times 0.2$ & $\mathrm{~S} 825$ & $\mathrm{~S} 825 \times 0.5$ \\
& $+\mathrm{S} 825 \times 0.8$ & & $\mathrm{~S} 826 \times 0.5$ \\
\hline Section & 13 & 14 & \\
\hline Location $(\mathrm{m})$ & 41.873 & 44.175 & \\
Shape & $\mathrm{S} 826$ & $\mathrm{~S} 826$ &
\end{tabular}

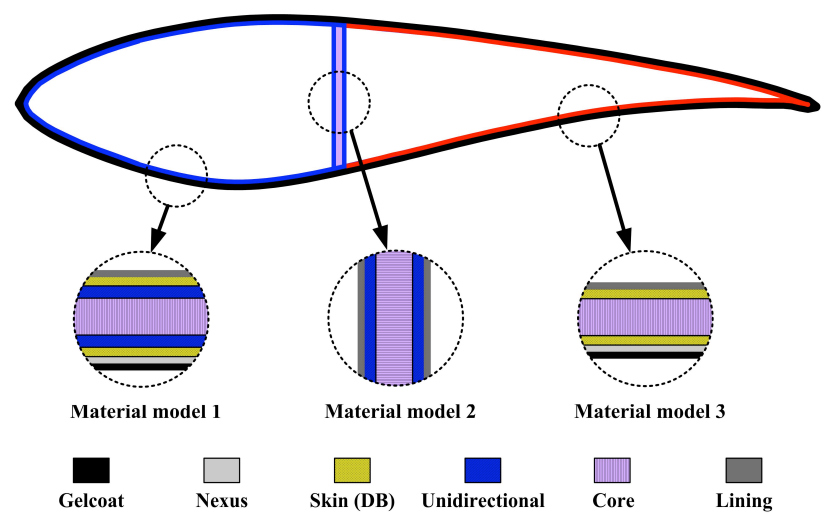

Fig. 2. Material layout of Type-A composite blade section

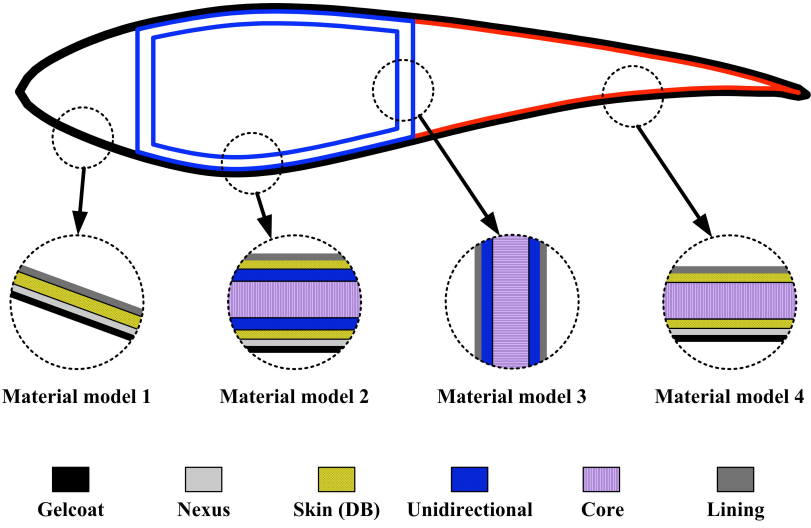

Fig. 3. Material layout of Type-B composite blade section

Table 2. Mechanical properties of the blade materials

\begin{tabular}{ccccccc}
\hline Material & $\begin{array}{c}\rho \\
\left(\mathrm{kg} / \mathrm{m}^{3}\right)\end{array}$ & $\begin{array}{c}\mathrm{E} \\
(\mathrm{Pa})\end{array}$ & $\begin{array}{c}\mathrm{G} \\
(\mathrm{Pa})\end{array}$ & $v$ & $\begin{array}{c}\sigma_{u t} \\
(\mathrm{~Pa})\end{array}$ & $\begin{array}{c}\sigma_{u c} \\
(\mathrm{~Pa})\end{array}$ \\
\hline Gelcoat & 1664 & -- & -- & -- & -- & -- \\
Nexus & 1830 & -- & -- & -- & -- & -- \\
Double-Bias & 1830 & $10.3 \mathrm{E}+9$ & $8.0 \mathrm{E}+9$ & 0.3 & $151 \mathrm{E}+6$ & $-174 \mathrm{E}+6$ \\
Lining & 1830 & $10.3 \mathrm{E}+9$ & $8.0 \mathrm{E}+9$ & 0.3 & $151 \mathrm{E}+6$ & $-174 \mathrm{E}+6$ \\
Unidirctional & 1860 & $37.0 \mathrm{E}+9$ & $4.1 \mathrm{E}+9$ & 0.31 & $986 \mathrm{E}+6$ & $-746 \mathrm{E}+6$ \\
$\quad$ Core & 128.1 & -- & -- & 0.3 & -- & -- \\
\hline
\end{tabular}

(a)

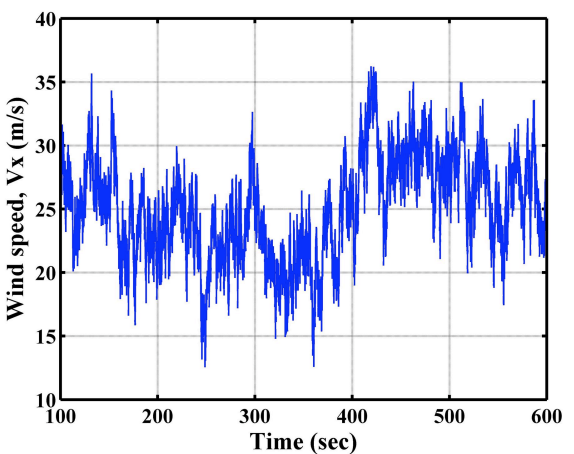

(b)

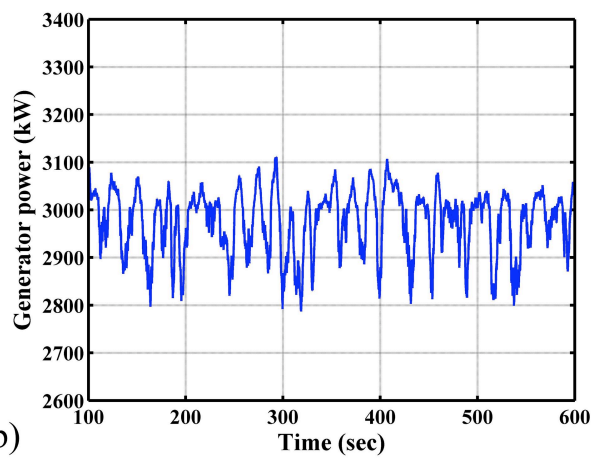

Fig. 4. (a) Simulated wind data at the center of the hub, and (b) generator output from the turbine

\subsection{Result of optimization procedure step one}

To achieve the optimum aerodynamic shape design for the blades using Eqs. (1) through (3), the designed lift coefficient $C_{L d}$ for a particular airfoil has to be established first. 
The lift coefficient $C_{L}$ of an airfoil is a function of the angle of attack, and so is the drag coefficient $C_{D}$. The coefficient $C_{L d}$ can be so determined that its corresponding angle of attack maximizes the ratio of $C_{L} / C_{D}$. An airfoil aerodynamics program, XFoil (Drela [15]), was employed to calculate the aerodynamic properties of the airfoils considered, and then a MATLAB script was coded to find the maximum ratio. The lift to drag ratios for the airfoil sections of the blade (sections 6 through 14 shown in Table 1) are plotted against the angles of attack as demonstrated in Fig. 5. Since the airfoil shapes for sections no. 13 and 14 are the same, i.e. S826, they share the plot as in Fig. 5(h). In executing the calculations using XFoil, a Reynolds number of $3 \times 10^{6}$ was assumed for all cases. The maximum lift to drag ratios $C_{L d} / C_{D}$ were found and are displayed in Table 3 along with their corresponding angles of attack $\alpha^{*}$, lift and drag coefficients.

Following the determination scheme for chord and twist angle distribution of the aerodynamically optimal blade, the local tip speed ratio $\lambda_{r}$, inflow angle $\phi_{r}$, twist angle $\beta_{r}$ and cord length $\mathrm{c}_{r}$ at difference sections are given in Table 4, with the designed tip speed ratio $\lambda_{d}$ set to 8 . Note that sections 1 through 5 have circular shapes with a diameter of $2.474 \mathrm{~m}$ and they assume the same twist angle as section 6 to facilitate the finite element modeling of the blade in the latter stage. The blade has larger chord lengths and twist angles for airfoil sections near the root and, except for section 12, sequentially diminishing chords and angles for sections approaching the blade tip.

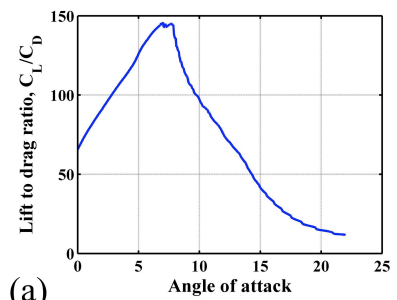

(a)
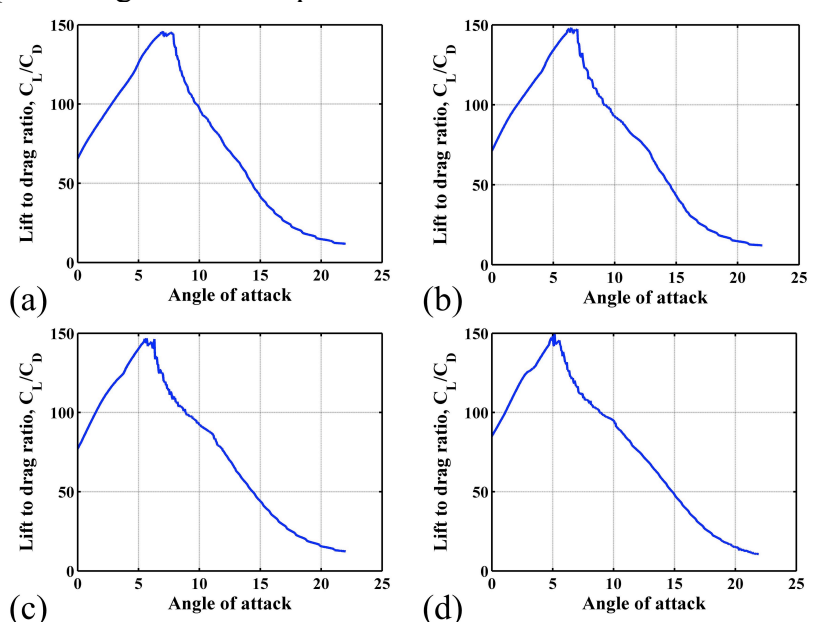

(c)
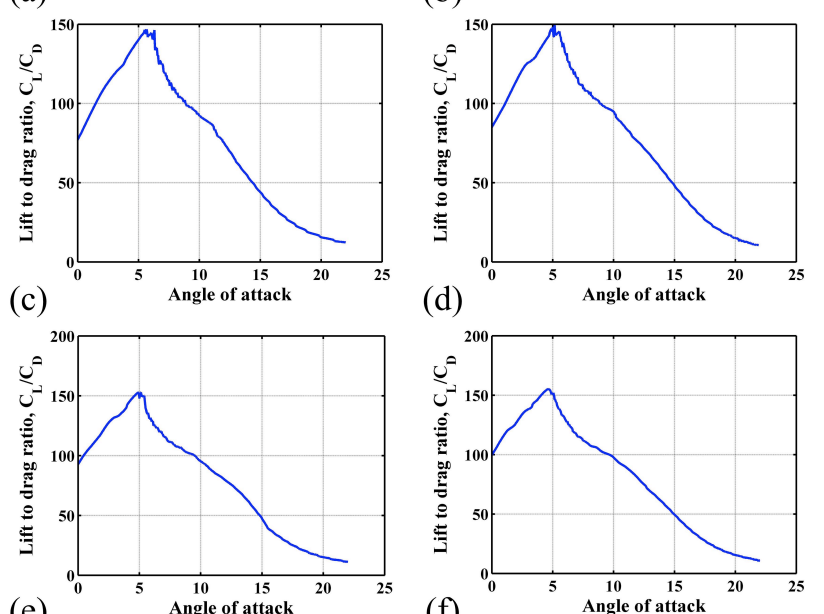

(e)

(d)

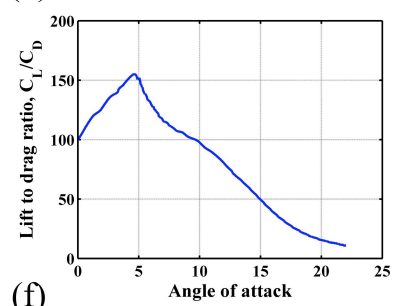

(f)
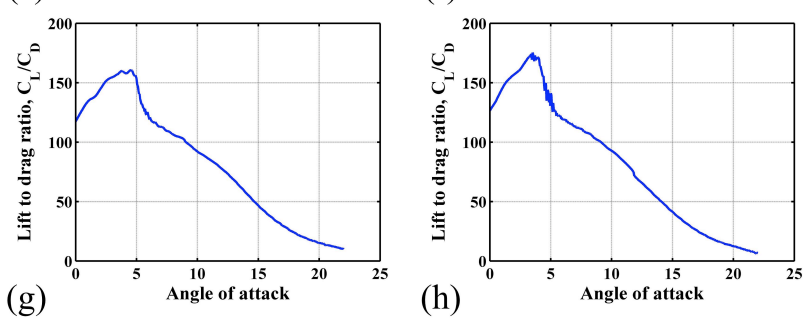

(h)

Fig. 5. Lift to drag ratios for airfoils at sections (a) 6, (b) 7 , (c) 8, (d) 9, (e) 10, (f) 11, (g) 12, and (h) 13 and 14
Table 3. Optimal aerodynamic properties of the airfoil sections

\begin{tabular}{ccccc}
\hline Section & 6 & 7 & 8 & 9 \\
\hline$\alpha_{d}\left(^{\circ}\right)$ & 7.00 & 6.45 & 5.65 & 5.15 \\
$\mathrm{C}_{L d}$ & 1.2883 & 1.2601 & 1.2038 & 1.1774 \\
$\mathrm{C}_{D}$ & 0.0088 & 0.0085 & 0.0082 & 0.0079 \\
$\mathrm{C}_{L d} / \mathrm{C}_{D}$ & 146.398 & 148.247 & 146.805 & 149.038 \\
\hline Section & 10 & 11 & 12 & 13 and 14 \\
\hline$\alpha_{d}\left(^{\circ}\right)$ & 4.90 & 4.65 & 4.55 & 3.50 \\
$\mathrm{C}_{L d}$ & 1.1744 & 1.1708 & 1.1818 & 1.0975 \\
$\mathrm{C}_{D}$ & 0.0077 & 0.0076 & 0.0074 & 0.0063 \\
$\mathrm{C}_{L d} / \mathrm{C}_{D}$ & 152.519 & 154.053 & 159.703 & 174.206 \\
\hline
\end{tabular}

Table 4. Chord and twist angle distribution of the aerodynamically optimal blade after design phase 1

\begin{tabular}{cccccc}
\hline Section & 1 thru 5 & 6 & 7 & 8 & 9 \\
\hline$\lambda_{r}$ & -- & 1.747 & 2.581 & 3.414 & 4.248 \\
$\phi_{r}\left({ }^{\circ}\right)$ & -- & 19.856 & 14.120 & 10.883 & 8.831 \\
$\beta_{r}\left({ }^{\circ}\right)$ & 12.856 & 12.856 & 7.670 & 5.233 & 3.681 \\
$\mathrm{c}_{r}(\mathrm{~m})$ & 2.474 & 3.730 & 2.863 & 2.360 & 1.979 \\
\hline Section & 10 & 11 & 12 & 13 & 14 \\
\hline$\lambda_{r}$ & 5.082 & 5.916 & 6.750 & 7.583 & 8.000 \\
$\phi_{r}\left({ }^{\circ}\right)$ & 7.422 & 6.396 & 5.618 & 5.008 & 4.750 \\
$\beta_{r}\left({ }^{\circ}\right)$ & 2.522 & 1.746 & 1.068 & 1.508 & 1.250 \\
$\mathrm{c}_{r}(\mathrm{~m})$ & 1.677 & 1.455 & 1.269 & 1.220 & 1.158 \\
\hline
\end{tabular}

\subsection{Result of optimization procedure step two}

\subsubsection{Simulation of the applied loads}

Employing the full-field wind data with a mean speed of 25 $\mathrm{m} / \mathrm{s}$ generated by TurbSim, the wind turbine simulation program FAST produced not only the generator output power shown in Fig. 4(b), but also accelerations of and moments and aerodynamic forces applied to the blade segments. There are 13 blade segments defined by those 14 crosssections, and the moments, forces and accelerations were assumed to be applied to the centers of the segments. Time histories of 600 seconds of everything at all 13 segment centers were simulated. Fig. 6 depicts the time histories between the 100 and 200 seconds of three acceleration components $\left(\mathrm{A}_{x}, \mathrm{~A}_{y}\right.$ and $\left.\mathrm{A}_{z}\right)$ and three moments $\left(\mathrm{M}_{x}, \mathrm{M}_{y}\right.$ and $\left.\mathrm{M}_{z}\right)$ acting on segment 1 , which is defined as the portion between crosssections 1 and 2, while Fig. 7 displays two aerodynamic forces $\left(\mathrm{F}_{n}\right.$ and $\left.\mathrm{F}_{t}\right)$. For the aerodynamic forces, the normal component $\mathrm{F}_{n}$ is in the direction normal to the plane of rotation and likewise for the tangential component $\mathrm{F}_{t}$ (Laino and Hansen [16]). Some quantities are apparently influenced by the rotor speed, which is $0.242 \mathrm{cps}$, as shown in Fig. 6(d), 6(e), 6(f) and 7(b). Multiplied by the mass of each segment, the accelerations lead to inertia forces acting on each segment. To simulate the extreme case that all the forces and moments at all 13 segments attain their maximum values at exactly the same time, the maximum values of the forces and moments were extracted from the histories, and then these forces and moments were simultaneously applied to the blade finite element model that will be described in the next subsection. 

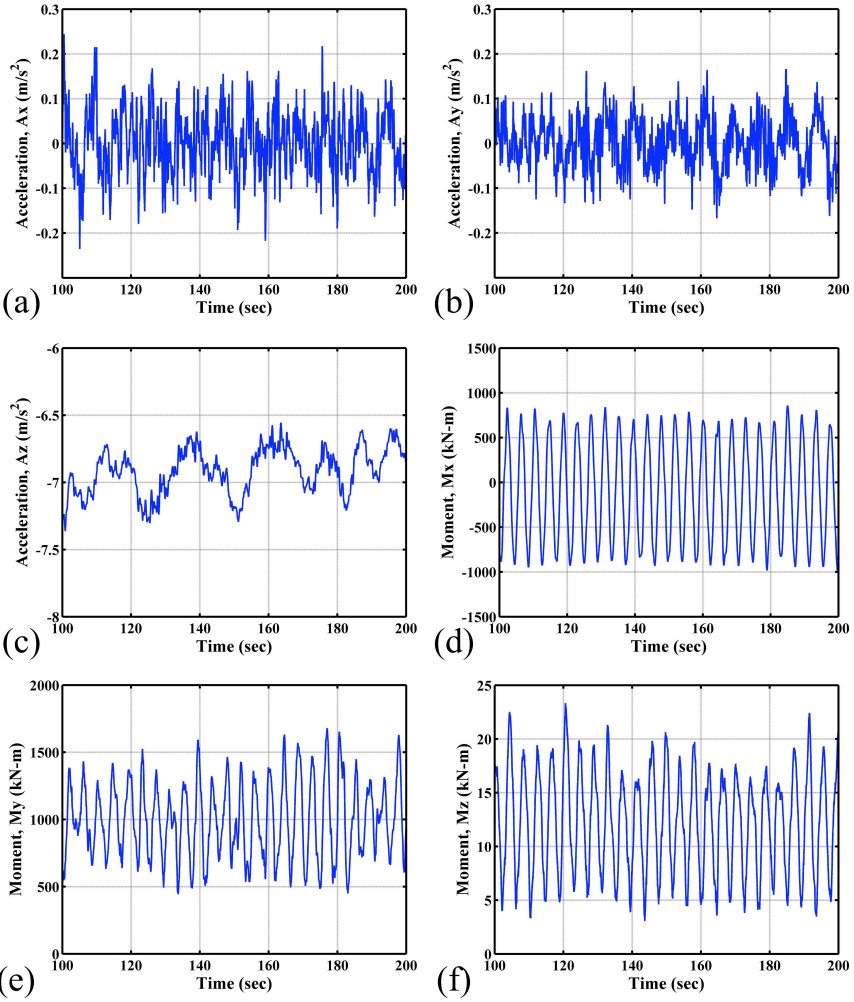

Fig. 6. Accelerations in (a) $\mathrm{x}$, (b) $\mathrm{y}$ and (c) $\mathrm{z}$ directions, and moments in (d) $x,(e) y$ and (f) $z$ directions of segment 1

(a)

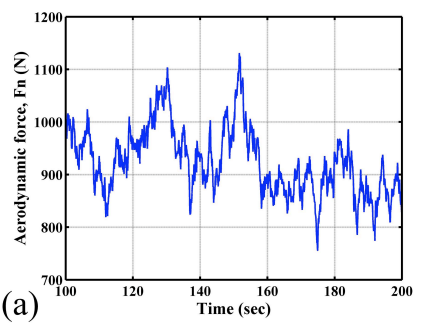

(b)

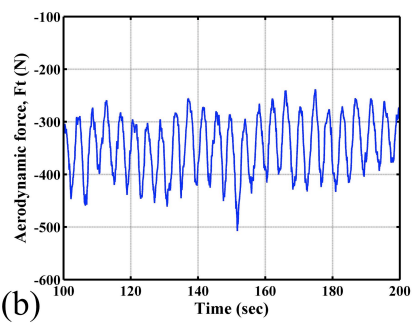

Fig. 7. Aerodynamic forces in (a) normal and (b) tangential directions, experienced by segment 1

\subsubsection{Finite element modeling for the turbine blade}

A parameterized finite element model of the aerodynamically optimized blade, with its circular-shaped blade root fixed as the boundary condition, was created using the ANSYS software. Fig. 8(a) shows the solid model of the blade and Fig. 8(b) displays more clearly from another viewing angle the airfoil sections with various chord lengths and twist angles. The finite element model composes of 8476 multilayer shell elements (SHELL99) for both the blade wall and box-spar reinforcement, and of 78 multipoint constraint elements (MPC184) for connecting the center nodes of the 13 segments to their respective cross-sectional perimeters. As for the material models used, since there are 4 material models for each blade segment (Fig. 3), 52 composite material models for the shell elements were defined overall. The maximum forces and moments were applied to those center nodes before a static finite element analysis was performed. In addition, modal analysis was also carried out to extract the blade's natural frequencies and mode shapes. In order to have a clear look inside the blade model, Fig. 8(c) illustrates the finite elements belonged to the lower half of the model.
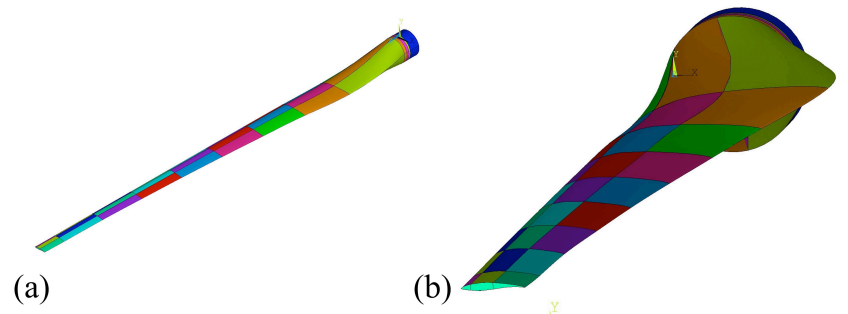

(c)

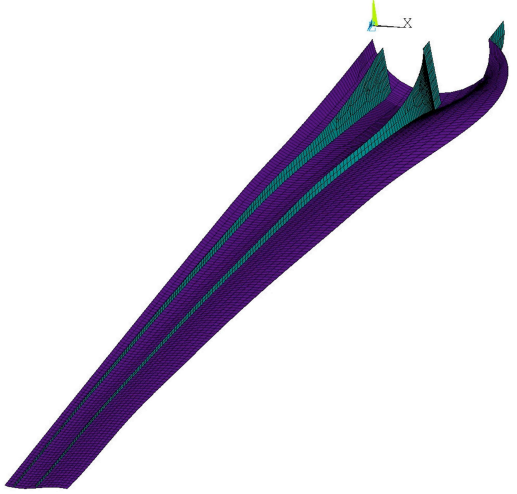

Fig. 8. (a) Solid model of the blade and (b) from another viewing angle, and (c) finite elements of the lower half of the blade model

\subsubsection{Structural optimization for the turbine blade}

The structural optimization problem, defined by Eqs. 4 through 8, was solved using ANSYS Parametric Design Language (APDL) with the first order optimization method under the ANSYS environment. When the first order optimization method is executed, the constrained optimization problem is transformed into an unconstrained one via penalty functions and derivatives are approximated using a forward difference approach. Exterior and extended interior penalty functions (Kirsch [17]) are applied, respectively, to the side constraints on the design variables and to the rest of the constraints. To form the search direction, the steepest descent method is used for the initial iteration, and conjugate directions are generated according to the Polak-Ribiere recursion formula (More and Wright [18]) for subsequent iterations. Moreover, the line search variable in the unconstrained optimization problem is solved by using a combination of a golden section algorithm and a local quadratic fitting technique.

The constants and limits in the optimization problem were set as follows: the total factor of safety $n_{f s}=2.21$ (Germanischer Lloyd [12]), $\sigma_{u t}=151 \mathrm{MPa}, \sigma_{d t}=\sigma_{u t} / n_{f s}=68.33 \mathrm{MPa}$, $\sigma_{u c}=-174 \mathrm{MPa}, \sigma_{d c}=\sigma_{u c} / n_{f s}=-78.73 \mathrm{MPa}, f_{r}=14.5 \mathrm{rpm}$ (the turbine rotor's rated speed) $=0.242 \mathrm{~Hz}, F_{m s}=0.25 \mathrm{~Hz}$. The setting of the value of $F_{m s}$ represents that the final optimized natural frequencies of the blade have to be more than twice as large as the rotor's rated speed, greatly reducing the possibility of resonance on the blades. Only the fundamental frequency (the first mode) is needed to achieve this goal, therefore the number of modes considered was set to 1 .

Also, there are 5 design variables selected and the first 4 design variables are all about the thickness values of the double-bias materials in the 4 circular segments: the first design variable $\left(x_{1}\right)$ is the thickness of the double-bias material in the first circular segment; the second $\left(x_{2}\right)$ is defined as the thickness in the first segment minus that in the second segment, i.e. the thickness difference between the first and 
second segments; the third and fourth $\left(x_{3}\right.$ and $\left.x_{4}\right)$ are the thickness difference between the second and third segments, and between the third and fourth segments, respectively. The rationale behind the definitions of $x_{2}, x_{3}$ and $x_{4}$ is to introduce a series of non-increasing thickness values for the doublebias materials. These circular segments have the thickest double-bias materials and account for a significantly large portion of the entire blade mass. The fifth design variable $\left(x_{5}\right)$ is a proportional factor such that the new thickness values of the unidirectional materials in segments 5 to 13 are determined by multiplying this factor to their initial thickness values. The use of the proportional factor as a design variable can greatly reduce the number of design variables. The thickness values of the double-bias materials in the 4 circular segments of the initial finite element model are, starting from the blade root segment: $110.88 \mathrm{~mm}, 110.88 \mathrm{~mm}, 85.74 \mathrm{~mm}$ and $45.53 \mathrm{~mm}$, which give the initial values of the design variables $x_{1}, x_{2}, x_{3}$ and $x_{4}$ as those shown in Table 5. Also shown in Table 5 are the initial values of $x_{5}$, constraints and the objective function.

After 30 iterations, the best feasible solution was chosen as the optimum solution, and the final optimal values of the design variables, constraints and the objective function are given in Table 5. Fig. 9(a) shows the iteration histories of the 5 design variables. During the structural optimization process, stress analysis and modal analysis of the blade model were repeated to acquire the maximum spanwise tensile and compressive stresses in the model and the natural frequencies of the blade. Fig. 9(b) demonstrates the iteration histories of the maximum tensile stress and the frequency difference between the first natural frequency of the blade and the rotor speed, and Fig. 9(c) depicts the iteration of the total mass of the blade, i.e. the objective function. Initially, the blade model was an infeasible design due to a high level of the maximum stress $(127.88 \mathrm{MPa})$, exceeding the upper limit of the stress constraint $(68.33 \mathrm{MPa})$. As the design variables were adjusting, especially the increasing design variable $x_{5}$, the total mass of the blade began to grow. After the process reaching the optimum, the mass had amplified from the initial $9773.9 \mathrm{~kg}$ to $15670 \mathrm{~kg}$. The situation that the blade mass increased quite significantly should be alleviated if the design variable $x_{5}$ was split into two or more proportional factors, each linking fewer segments. However, this would inevitably cast more burdens on the already heavy computational cost. Fig. 10(a) displays the stress distribution of the optimal blade model, and Fig. 10(b) and 10(c) the first and second natural frequencies $(0.584 \mathrm{~Hz}$ and $1.115 \mathrm{~Hz})$ and their corresponding mode shapes.

Table 5. Initial and optimal values of the variables

\begin{tabular}{cccc}
\hline \multicolumn{2}{c}{ Parameter } & Initial value & Optimal value \\
\hline & $x_{1}(\mathrm{~mm})$ & 110.88 & 96.02 \\
& $x_{2}(\mathrm{~mm})$ & 0 & 16.98 \\
Design & $x_{3}(\mathrm{~mm})$ & 25.1 & 25.83 \\
variables & $x_{4}(\mathrm{~mm})$ & 40.21 & 39.77 \\
& $x_{5}$ & 1.00 & 3.10 \\
\hline \multirow{3}{*}{ Constraints } & $\sigma_{t}(\mathrm{MPa})$ & $127.88^{*}$ & 68.05 \\
& $\sigma_{c}(\mathrm{MPa})$ & -67.04 & -59.23 \\
& $\left|f_{i}-f_{r}\right|(\mathrm{Hz})$ & 0.256 & 0.343 \\
\hline Obj. function & $m_{T}(\mathrm{~kg})$ & 9773.9 & 15670 \\
\hline
\end{tabular}

*Infeasible

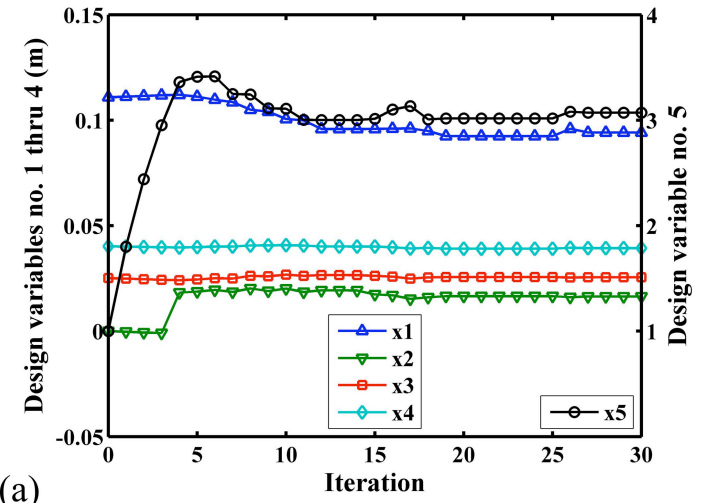

(a)

(b)
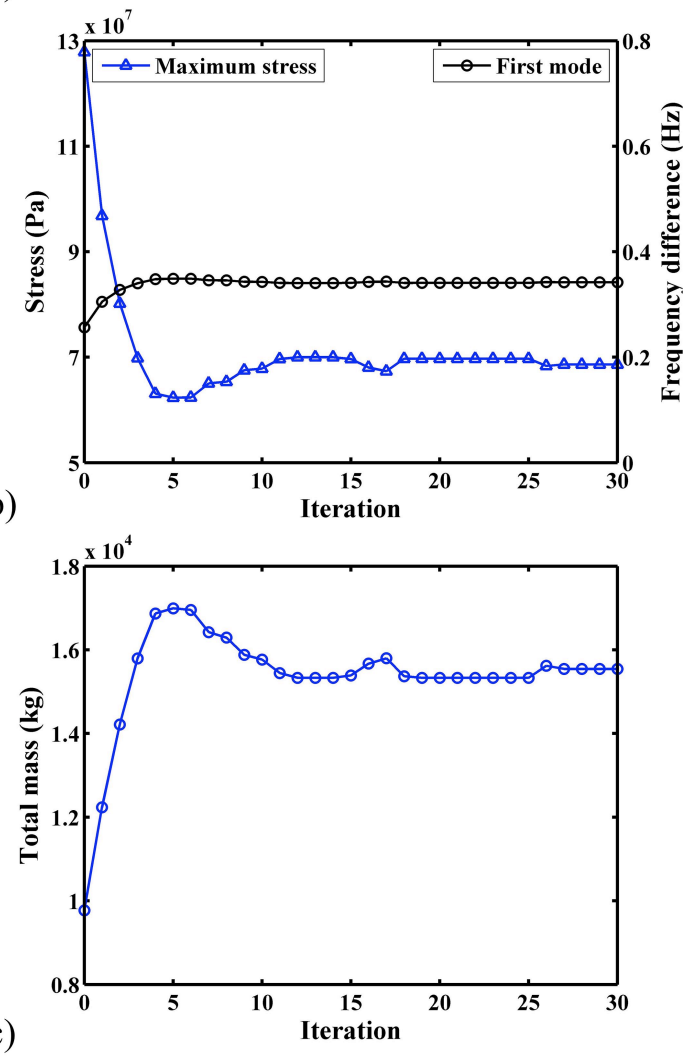

Fig. 9. Iteration histories of (a) the design variables, (b) maximum stress and frequency difference, and (c) total mass

\section{Conclusions}

This paper has presented a two-step procedure for the optimum design of composite wind turbine blades. A $3 \mathrm{MW}$, three-blade, horizontal-axis, upwind wind turbine with blades having cross-sections of NREL S818, S825 and S826 airfoil types was demonstrated as the design example. The result of the first step is the optimum cord lengths and twist angles of airfoils of the blade cross-sections along the blade spanwise direction. Generally, the aerodynamically optimized chord lengths and twist angles are larger near the blade root and sequentially diminish when approaching the blade tip. A parameterized finite element model of the aerodynamically optimized blade was created using the ANSYS software. A full-field turbulence with a mean speed of $25 \mathrm{~m} / \mathrm{s}$ was simulated and applied to the wind turbine to produce time series of accelerations, moments and aerodynamic forces acting on the blade segments. Subsequently, the maximum values of the forces and moments were extracted and then simultaneously imposed to the blade finite element model to replicate 
the extreme case. The second step provides optimal material distribution for the composite blade. The results have shown that the initial blade model was an infeasible design due to a high level of the maximum stress, exceeding the upper limit of the stress constraint, but eventually the process converged to a feasible solution with the expense of increased total mass of the blade.

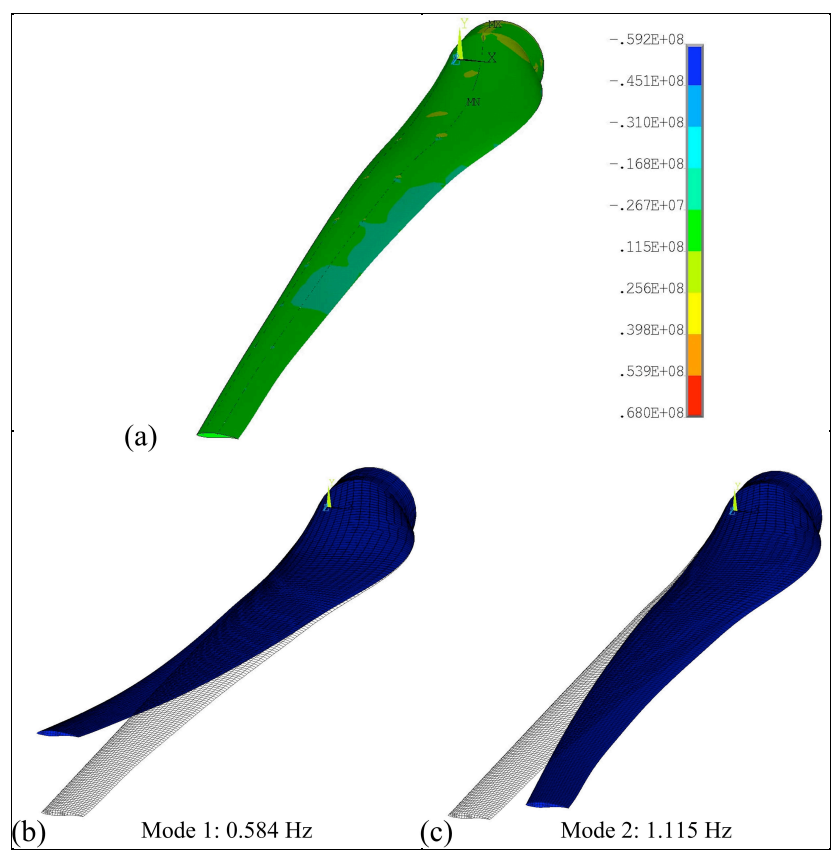

Fig. 10. (a) Stress distribution of the optimal model, (b) the first mode shape and its natural frequency, and (c) the second mode shape and its natural frequency

\section{Acknowledgement}

This research work has been supported by the National Science Council of Taiwan, ROC under grant no. NSC 99-2221E-236-008. The financial support is gratefully appreciated.

\section{References}

1. W.A. Timmer, An overview of NACA 6-digid airfoil series characteristics with reference to airfoils for large wind turbine blades, in Proceedings of the $47^{\text {th }}$ AIAA Aerospace Science Meeting Including the New Horizons Forum and Aerospace Exposition, Orlando, Florida, USA (2009).

2. K.Y. Maalawi, M.A. Badr, A practical approach for selecting optimum wind rotors. Renewable Energy. 28, 803-822 (2003).

3. K.Y. Maalawi, H.M. Negm, Optimal frequency design of wind turbine blades. Journal of Wind Engineering and Industrial Aerodynamics. 90, 961-286 (2000).
4. V. Díaz Casás, F. Lopez Peňa, R.J. Duro, Automatic design and optimization of wind turbine blades, in Proceedings of International Conference on Computational Intelligence for Modeling Control and Automation, and International Conference on Intelligent Agents, Web Technologies and Internet Commerce, CIMCA-IAWTIC'06 (2006).

5. V. Díaz Casás, F. Lopez Peňa, R.J. Duro, A. Lamas, Automatic aerodynamic design of a wind turbine through evolutionary techniques, in IEEE Workshop on Intelligent Data Acquisition and Computing System: Technology and Applications, Sofia, Bulgaria (2005).

6. M. Jureczko, M. Pawlak, A. Mężyk, Optimization of wind turbine blades. Journal of Material Processing Technology. 167, 463-471 (2005).

7. A.J. Vitale, A.P. Rossi, Computational method for the design of wind turbine blades. International Journal of Hydrogen Energy. 33, 3466-3470 (2008).

8. D.J. Malcolm, A.C. Hansen, WindPACT Turbine Rotor Design Study, Subcontract Report NREL/SR-500-32495, National Renewable Energy Laboratory, Golden, Colorado, USA, 2006.

9. G. Bir, P. Migliore, Preliminary Structural Design of Composite Blades for Two- and Three-Blade Rotors, Technical Report NREL/TP-500-31486, National Renewable Energy Laboratory, Golden, Colorado, USA, 2004.

10. D.A. Griffin, WindPACT Turbine Design Scaling Studies Technical Area 1-Composite Blades for 80- to 120-Meter Rotor, Subcontract Report NREL/SR-500-29492, National Renewable Energy Laboratory, Golden, Colorado, USA, 2001.

11. D.A. Spera, Wind Turbine Technology: Fundamental Concepts of Wind Turbine Engineering (ASME press, New York, 1994)

12. Germanischer Lloyd, Rules and Guidelines IV-Industrial Services-Guideline for the Certification of Wind Turbine, Germanischer Lloyd Industrial Services GmbH, Hamburg, Germany, 2003.

13. B.J. Jonkman, M.L. Buhl, TurbSim User's Guide for Version 1.40, National Renewable Energy Laboratory, Golden, Colorado, USA, 2008.

14. M.J. Jason, L.B. Marshall, Jr., FAST User's Guide, Technical Report NREL/EL-500-38230, National Renewable Energy Laboratory, Golden, Colorado, USA, 2005.

15. M. Drela, XFOIL 6.9 User Primer (MIT Press, Cambridge, MA, USA, 2001)

16. D.J. Laino, A.C. Hansen, User's Guide to the Wind Turbine Dynamics Computer Software AeroDyn, Windward Engineering, Salt Lake City, Utah, USA, 2001.

17. U. Kirsch, Structural Optimization: Fundamentals and Applications (Springer-Verlag, Berlin, 1993)

18. J.J. More, S.J. Wright, Optimization Software Guide (SIAM Publications, Philadelphia, 1993) 